98.6 Degrees: The Art of Keeping Your Ass Alive Cody Lundin

Layton, UT: Gibbs Smith, 2003

US \$16.95, 240 pages, soft cover

If you read Wilderness \& Environmental Medicine, chances are that you venture into the wilderness periodically in search of solace, fun, adventure, photos, or something else only found in the great outdoors. The vast majority of such trips into the wilderness will go well-be they day hikes or multi-week expeditions. Should something go wrong and you find yourself in a survival situation-say, getting injured, getting separated from your pack or your party, surviving a small plane crash, getting lost, or being unable to find your vehiclethen you will need to keep your wits about you, seek shelter and water, and most importantly, keep your body temperature at $98.6^{\circ} \mathrm{F}\left(37^{\circ} \mathrm{C}\right)$ - hence the title.

Cody Lundin lives in Arizona. He has spent lots time living in a tent and years living in the woods in a leanto, and he has an aboriginal living school where he teaches wilderness survival skills. He speaks with the authority of one who really knows from experience, albeit with an irreverent and humorous tone. He knows his stuff, and his book goes deeply into the details of just what equipment you will need to survive. For example, there is a 7-page section just on the various types of matches and how to prepare them so they will most likely still be working when you really need them. He goes deeply into the details of why you ought to carry dental floss, duct tape, and a condom in your survival kit (it's a wonderful collapsible water container). He has a section on how to select a knife for your survival kit and what characteristics are most important. He also, of course, gives thorough explanations of just what to do with all these things once you have them, how to use them, and some examples of improvisation.

However, the most important part of the book is not the chapter on how to assemble the things that comprise the survival kit but the other 13 chapters on just what is likely to kill you and what it takes to survive. It turns out that the most important item in your survival kit is right between your ears, and Lundin tries to emphasize that point with chapters on fear, panic, clothing issues, shelter, what to leave behind when you go into the wilderness to aid your rescuers, how to attract rescue, etc. He spends some time reviewing basic physiology and thermoregulation and spends a lot of time talking about attitude, preparedness, and general principles of survival aside from the equipment. He provides a few easy to remember mnemonics and principles that can be practiced in the comfort of your backyard.

The book is written with a humorous tone and is re- plete with cartoon-like drawings of characters (strange little critters that I could have done without!) that try to emphasize the points that Lundin makes throughout. There is a section of color photos of survival kit details and, of course, info on how to contact Lundin and enroll in his survival school. (One of these days. ... When I have some spare time. ...)

Overall, this book should prove to be a valuable addition to the library of nearly anyone who ventures outdoors. I would recommend it as such. Read it, think about it, gather up a kit, and read it again. Practice some of the skills regularly as you can (like making a fire out of cold, wet tinder in a windstorm), and you will be prepared to come back from wherever you go alivewhich is the ultimate goal.

Rob Hamilton, MD

Redding, CA, USA

\section{The Active Woman's Guide to Pregnancy}

Aneema Van Groenou, MD

Berkeley, CA: Ten Speed Press, 2004

US \$16.95, 300 pages, soft cover

When Aneema Van Groenou asked me to write a book jacket quote for The Active Woman's Guide to Pregnan$c y$, I was flattered. One of the joys of being a teacher is watching young authors blossom as writers, particularly when their topic is important and enthusiasm is infectious. Another great feeling is uncovering a new niche in wilderness medicine. Women's health has only recently been appropriately emphasized, so advice for pregnant women lags behind offerings for other special interest groups. With this guide, active women are encouraged and counseled to get outdoors and make the most of it.

As much as any other group, pregnant women are the recipients of varying recommendations about activities, diet, drug use, and travel. Much of what is written is anecdotal. So, it is high time to offer some reasons for our guidance. This book stays within bounds and is conservative in its content and recommendations. For a first effort, that is the correct approach. It is an ambitious undertaking. With the portions that have been well done come some sections in need of improvement. The overall product is worth the effort. I anticipate that the author will receive a fair amount of feedback that will be taken into consideration for the next edition.

The structure of topics is to enumerate the benefits of staying active then to briefly discuss health concerns by trimester of pregnancy, elucidate outdoor gear for pregnancy, move on to first aid, and then enter the major part 